\title{
The menstruation experience: Attitude dimensions among South African students
}

\author{
Anita Padmanabhanunni and Thelma Fennie
}

\begin{abstract}
This study aimed to investigate the attitudes and experiences regarding menstruation among undergraduate women at a historically disadvantaged South African university. A total of 255 women participated in the study. The majority of participants were black women (coloured $=55 \%$; African $=29.2 \%$ ). They responded to the Menstrual Attitudes Questionnaire (MAQ) and a demographic questionnaire. Data were analysed using descriptive statistics and ANOVA with post-hoc tests. The majority of women in the study (78\%) had positive attitudes towards menstruation, viewing it as a natural event that can be anticipated and predicted. However, many of the women (51-58\%) perceived it as debilitating and bothersome to everyday living. Menstruation was perceived by women as impacting on participation and performance in higher education, suggesting that the provision of tertiary education for previously disadvantaged groups needs to consider the needs of women who experience difficulty managing menstruation. The provision of material resources, education in self-care strategies and distribution of information to normalise menstruation may assist the adverse impact of menstruation on their higher education experience.
\end{abstract}

\section{Introduction}

Menarche, the first menstrual period, typically occurs between the ages of 12 and 15 and is a critical milestone in the transition to young adulthood (Nagar \& Aimol, 2010; McMahon et al., 2011). However, it remains largely under-researched in developing world contexts and there is a significant need to understand present-day experiences of menstruation, particularly among young women living in societies in transition such as South Africa. Studies among Western women have shown that their attitudes are generally negative and that menstruation is largely experienced as shameful, debilitating and disruptive of activities and social interactions (Chrisler, Marván, Gorman, \& Rossini, 2015). In developing world contexts, however, women's experience of menstruation and the impact of sociocultural and demographic factors on their attitudes towards menstruation remain largely under-researched.

Women's attitudes towards menstruation are complex and need to be explored in the context of their lived experiences (Chothe et al ., 2014; Kumar \& Srivastava, 2011; Sommer, Hirsch, Nathanson, \& Parker, 2015; Wong \& Khoo, 2011). The present study 
focused on investigating the attitudes and experiences regarding menstruation among a sample of young women attending a historically disadvantaged ${ }^{1}$ South African university that predominantly caters to students from black communities.

South African research on women's experiences of menstruation come from studies focusing on HIV/ AIDS and reproductive health issues broadly (Laher et al ., 2010; Mkhwanazi, 2010; O’Sullivan, Cooper-Serber, Kubeka \& Harrison, 2007; Wood \& Jewkes, 2006) . Overall, these studies reported that young South African women experience menstruation as stigmatising and view themselves as being "debased" by it . For instance, Laher et al. (2010) found that South African women perceived menstrual blood as reducing their male partners' sexual desire, while Wood and Jewkes (2006) reported that for young women menarche meant increased risk of pregnancy and signalled the onset of contraceptive use. Nevertheless, there is limited information regarding South African women's attitudes towards menstruation and the extent to which it impacts on their daily lives and educational experiences .

Studies from a number of African countries, including Kenya (Jewitt \& Ryley, 2014), Tanzania (Kirk \& Sommer, 2006), Malawi (Grant, Lloyd \& Mensch, 2010) and Ghana (Sommer, Ackatia-Armah, Connolly, \& Smiles, 2015) have reported that young women appraise menstruation as the most significant social stressor and barrier to schooling. International studies on the menstrual-related experiences of young women attending college in Britain (Anastasakis, Kingman, Lee, Economides, \& Kadir, 2008), Japan (Yamamoto, Okazaki, Sakamoto, \& Funatsu, 2009), India (Sharma, Malhotra, Taneja, \& Saha, 2008; Singh, Kiran, Singh, Nel, Singh, \& Tiwari, 2008) and Turkey (Pinar, Colak \& Oksuz, 2011) have corroborated this. Menstrual- related physical symptoms and psychological distress was experienced by women as hindering their full participation in university life . Furthermore, poverty and limited access to resources often mean that girls and women living in these contexts cannot afford sanitary products, leading to missed classes or dropping out of school (Kirk \& Sommer, 2006). In the South African context, this may also be true for girls and women from historically disadvantaged communities, particularly those living in informal settlements and other low socio-economic areas, owing to their limited access to resources needed to manage menstruation .

In terms of the existing literature, five attitudinal- related dimensions regarding menstruation have been identified, namely menstruation as "a debilitating event", "a bothersome event", "a natural event", "an event that can be predicted and anticipated" and "denial of the effect of menstruation" (Brooks-Gunn \& Ruble, 1980; 1986). The extent to which the menstrual experiences of young women attending university in transitional societies such as South Africa correspond to the existing literature is unclear.

This study sought to answer the following research questions:

1. How do young South African women in higher education characterise their experience of menstruation? 
2. How do the attitudes towards menstruation held by young South African students vary in terms of demographics?

3. How do South African students perceive menstruation as impacting on their attendance and performance at university?

\section{Method}

\section{Participants and setting}

A total of 255 women enrolled for undergraduate studies at a historically disadvantaged South African university participated in the study. The majority of participants were 19 (30\%) and 21 years old $(28,8 \%)$. With regard to race, the majority were coloured (55\%), followed by black (29.2\%) and white (7.7\%). Home languages for participants included English (43.5\%), African languages (isiXhosa and isiZulu) (26\%) and Afrikaans (25.5\%). Most participants lived in a household where their primary caregiver was employed (71 $.9 \%)$. The majority of participants either lived with both their parents $(51.5 \%)$ or in singleparent households (30.4\%). Most participants lived in urban areas (61.9\%), with some participants living in a township (26.1\%) or in rural areas (10\%).

\section{Measuring instruments}

Experiences and attitudes regarding menstruation Participants completed the Menstrual Attitudes Questionnaire (MAQ: Brooks-Gunn \& Ruble, 1980; 1986), a 33-item measure consisting of five factor subscales, namely "menstruation as a debilitating event" (12 items), "menstruation as a bothersome event" (6 items), "menstruation as a natural event" (4 items), "menstruation as an event that can be predicted and anticipated" (4 items), and "denial of any effects of menstruation" (7 items). MAQ items are scored on a five-point Likert scale ( $1=$ strongly disagree; $5=$ strongly agree). Internal consistency Cronbach's alpha of 0.77 to 0.91 for scores from the MAQ subscales have been reported (Brooks-Gunn \& Ruble, 1980; 1986; Chou, Lu, Pu, \& Lan, 2008; Lu, 2001).

\section{Biographical and social context variables}

Participants self-reported on personal demographics (i .e. age, race, home language, head of household employment status, area of residence, and primary caretaker). They also selfreported on socio-contextual variables such as whether menstruation was freely spoken about in their family, who they felt most comfortable speaking to about menstruation, whether they experienced financial difficulties purchasing sanitary products, and whether they had ever been absent from university due to menstruation.

\section{Procedure}

Ethical approval for the study was granted by the University of the Western Cape through the Department of Psychology. Respondents provided written informed consent for participation. To be included in the study, women had to be above the age of 18 and have already attained menarche. Participants were recruited by advertising the aims of the project to students prior to lectures . Participation was on a voluntary basis. Women wanting to participate in the study were requested to remain in the lecture theatre after their lecture. Questionnaires were administered over a one-week period. The nature and aims of 
the research were described to all respondents, as was the content and completion requirements of the questionnaire .

\section{Results}

Table 1 presents the means, standard deviations and reliability coefficients (coefficient alpha) for the MAQ subscales. As seen in Table 1, the majority of participants (78\%) agreed that menstruation was a natural event, that it could be anticipated and predicted (60\%), and that it was debilitating (51\%) and bothersome (58\%). A minority (23\%) denied the negative effects of menstruation .

Table 2 provides the results of statistical analysis of differences on a number of demographic variables in relation to the MAQ subscales. As can be seen from the Table, ANOVA indicated signifi results for demographic and socio-contextual factors on the MAQ subscales .

\section{Age and race effects}

Tests of mean comparisons across age indicated significant differences in anticipatory attitudes between women in the 21 years and older age group (Mean $=3.44, \mathrm{SD}=0.68$ ) compared to younger women of 20 years or younger (Mean $=3 \cdot 79, \mathrm{SD}=0.64$ ).

There were also significant attitudinal differences in terms of race with black (Mean $=3$ $.14, \mathrm{SD}=0.49$ ) and coloured women (Mean $=3.15$, SD $=0.53$ ) reporting greater endorsement of "menstruation as a debilitating event", that nevertheless could be "anticipated and predicted", compared to white women (Mean $=2.67, \mathrm{SD}=0.61$ ). In addition, black women (Mean $=2.29, \mathrm{SD}=0.86)$ and coloured women (Mean $=2.03, \mathrm{SD}$ $=0.60$ ) endorsed more attitudes of denial of the negative effects of menstruation compared to white women $($ Mean $=1.91, \mathrm{SD}=0.36),(p>0.05)$.

Table 1. Descriptive statistics for the study variables

\begin{tabular}{lccccc}
\hline & $n$ & Agree $\%$ & Mean & SD & Coefficient alpha \\
\hline Debilitating & 239 & 50.76 & 3.10 & 0.55 & 0.66 \\
Natural event & 243 & 78.23 & 4.00 & 0.70 & 0.68 \\
Bothersome & 232 & 57.55 & 3.45 & 0.66 & 0.50 \\
Denial & 244 & 22.54 & 2.10 & 0.69 & 0.56 \\
Anticipation & 249 & 60.38 & 3.58 & 0.71 & 0.54 \\
\hline
\end{tabular}




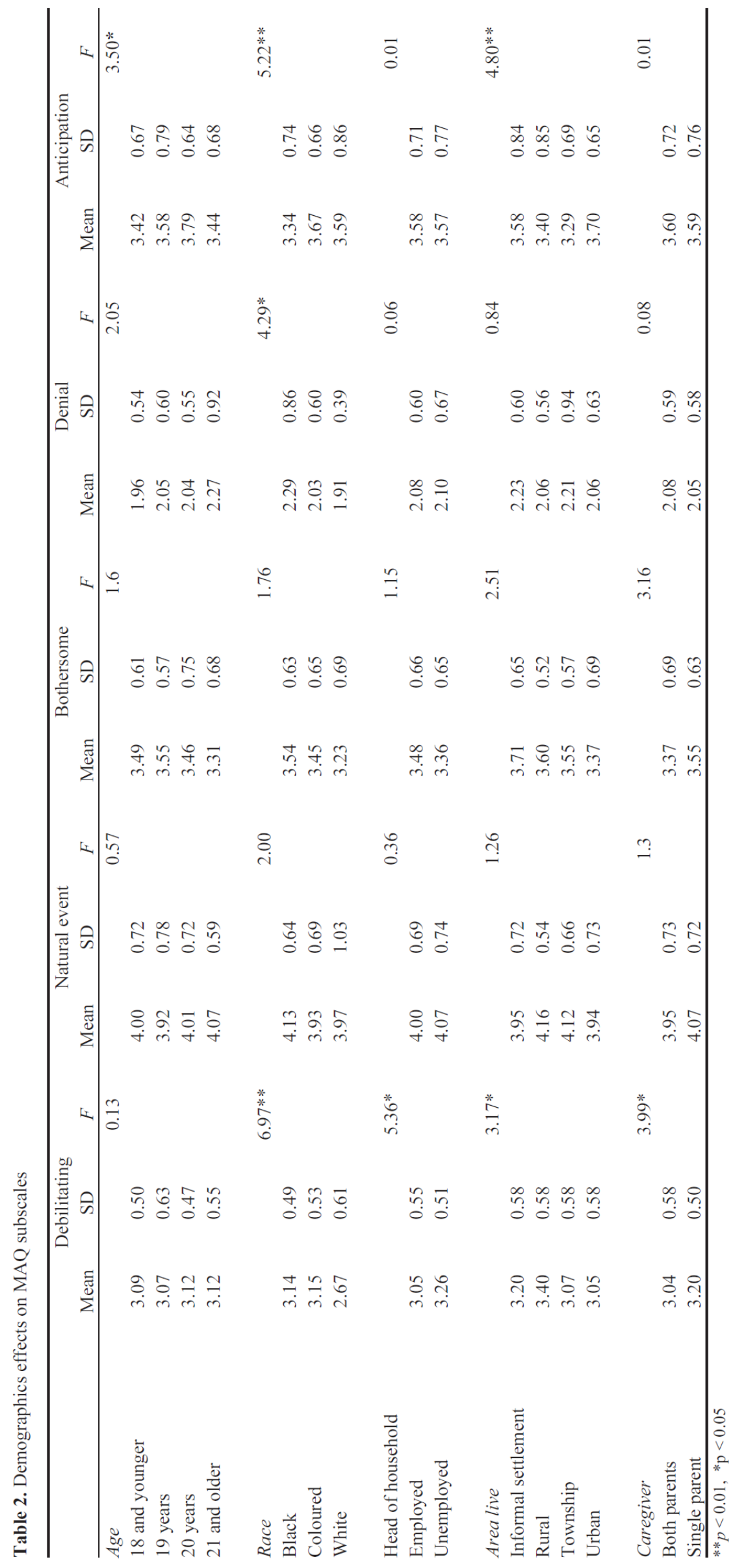


Socio-contextual and education participation effects Endorsement of menstruation as a debilitating event was found to be more likely among women with a history of being cared for by a single parent (Mean $=3.20, \mathrm{SD}=0.50$ ), from a rural area (Mean $=3.40, \mathrm{SD}$ $=0.58)$ and where the head of the household was not employed (Mean $=3.26, \mathrm{SD}=0.51),(p$ $>0.05$ ). In addition, women residing in low socio-economic neighbourhoods (also called townships) reported less anticipatory attitudes with regard to menstruation (Mean $=3.29$, $\mathrm{SD}=0.69$ ) compared to those from economically well-off urban settings (Mean $=3 \cdot 70$, SD $=0.65),(p>0.05)$.

Table 3 provides the results from analysis of differences on socio-contextual factors in relation to attitudes. As can be observed from Table 3, socio-interactional variables such as "freely talked about" $(F=8.79, p<0.01)$ and "comfortable speaking to" $(F=4.98, p<0.01)$ were associated with greater perceptions of menstruation as debilitating and as an event that could be anticipated and predicted .

Women reporting to have "missed classes" as a result of menstruation were more likely to endorse debilitating (Mean $=3 \cdot 36, \mathrm{SD}=0.48)(p<0.01)$ and anticipatory attitudes (Mean $=3.89, \mathrm{SD}=0.59)(p<0.01)$ compared to those who reported not missing classes . In addition, women who reported that menstruation affected their academic performance had higher debilitating (Mean $=3.35, \mathrm{SD}=0.57)(p<0.01)$ and anticipatory attitudes (Mean $=3.84, \mathrm{SD}=0.69)(p<0.01)$.

\section{Discussion}

The majority of women from the present study reported viewing menstruation as a natural event that can be anticipated and predicted, and also as debilitating and bothersome. Findings are consistent with those from previous related studies (Bramwell, Biswas, \& Anderson, 2002; Chou et al ., 2008; Lu, 2001; Wong \& Khoo, 2010) . Demographic factors including age, race, employment status of head of household and area of residence were related to reported menstruation experience-related attitudes. Age effects are likely explained by heightened self-consciousness regarding menstruation among younger women, compared to older women (Johnston- Robledo, Sheffield, Voigt, \& WilcoxConstantine, 2007). Only a small proportion of women in the study reported attitudes indicative of the denial of the negative effects of menstruation (see also Chou et al ., 2008; Lu, 2001).

Black and coloured women in the study reported more debilitating and anticipatory attitudes compared to white women. The reasons for these differences in race are not apparent. However, previous studies (e.g. Eswi, Helal, \& Elarous, 2012; Yeung, Tang, \& Lee, 2005) reported that women who were socialised to view menstruation negatively are more likely to perceive it as debilitating. These differences in perceptions of menstruation as debilitating may also be explained by a history of poverty among black and coloured women owing to decades of apartheid policies that impacted on their access to resources . 
Previous studies among adolescent girls (Cooper \& Koch, 2007; Kumar \& Srivastava, 2011) have consistently reported socio-economic deprivation as a signifi stressor that may contribute to menstruation being perceived as more debilitating . For women experiencing socio-economic deprivation, it is possible that denying the negative effects of menstruation represents one way of coping when resources to manage menstruation are not available. Limited resources as well as menstrual- related physical and psychological distress may account for missed lectures and the reported impact on academic performance.

Women from families with more open communication about menstruation were less likely to deny the negative effects of menstruation. This might be explained by findings that the nature of information conveyed regarding menstruation may serve to normalise it, and impacts on attitudes (Adinma \& Adinma, 2008; Yeung et al., 2005).

\section{Implications of the study for women in higher education}

The study provides some evidence to suggest that the provision of tertiary education for previously disadvantaged groups should take into account the unique needs of women who experience difficulty managing menstruation (see also Department of Higher Education and Training, 2013; Higher Education South Africa, 2007). For instance, student support services need to provide support for women students to manage menstruation within the university environment, including material resources, education in self-care strategies and information to normalise the menstruation experience (Chothe et al ., 2014; Sommer, 2009). This type of support may work towards addressing some of the secrecy and shame that may be experienced by some women students and also assist in reducing the potentially adverse impact of menstruation on women's educational experiences.

\section{Limitations of the study}

This study has several limitations. The small sample size and low reliability of certain of the subscales means that results need to be interpreted with caution. The study is also limited in its scope and applicability as a consequence of sampling only women in tertiary education institutions. Follow-up studies should continue to investigate attitudes, particularly among non-student populations and further clarify the influence of sociocultural factors on women's attitudes and experiences regarding menstruation.

\section{Conclusion}

The study found that South African students view menstruation as a natural event that can be anticipated and predicated, but they also experience it as bothersome and debilitating.In addition, demographic and socio-contextual factors correlated with attitudes towards menstruation. In that respect a history of material deprivation was associated with experience of menstruation as debilitating. For some women, their menstruation experience impacted on attendance and participation at university, reflecting the gendered influences on them. 


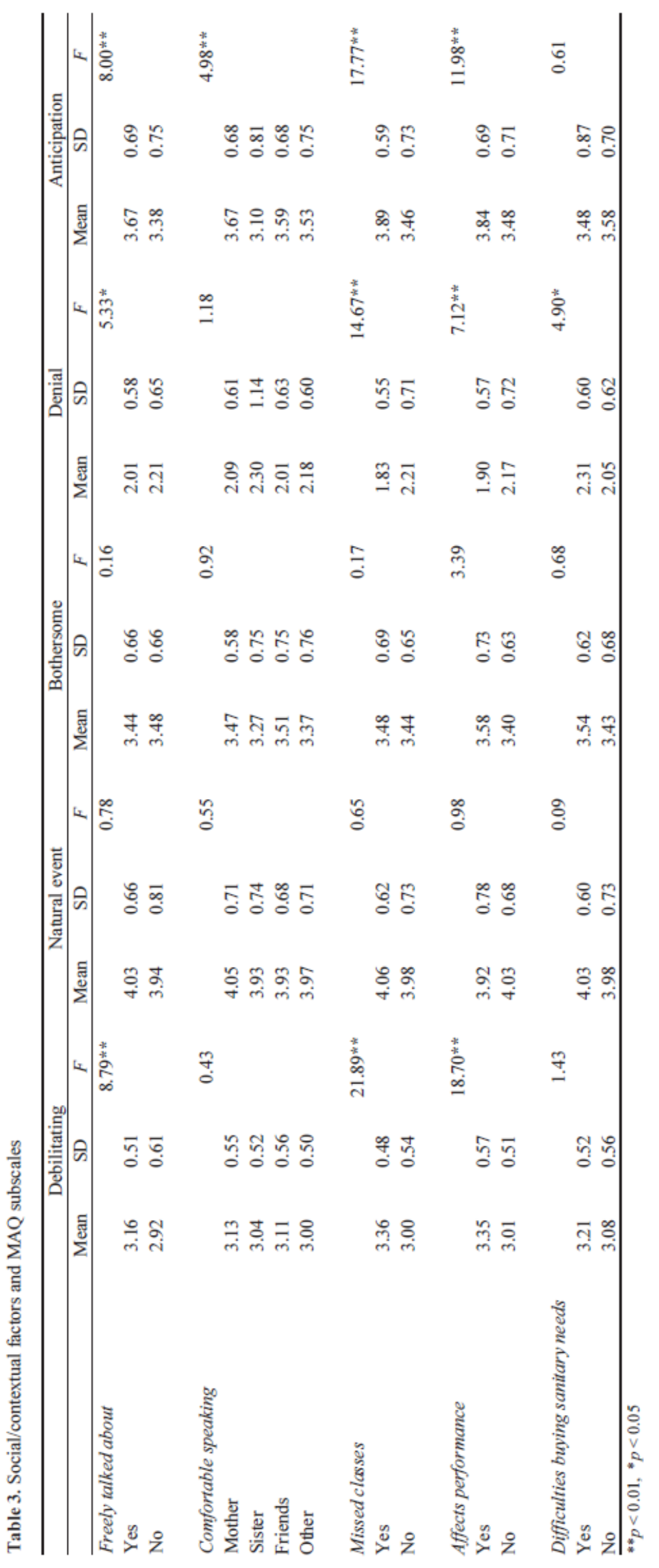




\section{End notes}

1 The term historically disadvantaged university is used to refer to those institutions in South Africa that were created under apartheid to cater for specific racial groups and were significantly disadvantaged in terms of allocation of resources and support from the government at the time. 


\section{References}

Adinma, E. D ., \& Adinma, J . I . (2008). Perceptions and practices on menstruation amongst Nigerian secondary school girls . African Journal of Reproductive Health, 12(1), 7483.

Anastasakis, E., Kingman, C. E., Lee, C . A., Economides, D . L ., \& Kadir, R . A . (2008). Menstrual problems in university students: An electronic mail survey. In Vivo (Athens, Greece), 22(5), 617-620. http://dx .doi .org/10.1089/cyber .2010.0135.

Bramwell, R.S., Biswas, E.L., \& Anderson, C. (2002). Using the menstrual attitude questionnaire with a British and an Indian sample. Journal of Reproductive and Infant Psychology, 20(3), 159-170 . http://dx .doi . org/10 $.1080 / 026468302760270818$.

Brooks-Gunn, J ., \& Ruble, D . N . (1980). The menstrual attitude questionnaire . Psychosomatic Medicine, 42(5), 503-512 . http://dx .doi .org/10 .1097/00006842-198009000-00005 .

Brooks-Gunn, J ., \& Ruble, D . N . (1986) . Men's and women's attitudes and beliefs about the menstrual cycle . Sex Roles, 14(5-6), 287-299 . http://dx .doi .org/10 .1007/BFo0287580.

Chothe, V., Khubchandani, J ., Seabert, D ., Asalkar, M ., Rakshe, S., Firke, A., . . . Simmons, R . (2014) . Students' perceptions and doubts about menstruation in developing countries: A case study from India . Health Promotion Practice, 15(3), 319-326 . http://dx .doi .org/10 .1177/1524839914525175.

Chou, Y. C., Lu, Z . J ., Pu, C . Y., \& Lan, C .-F . (2008). Predictors of female worker attitudes towards menstruation and the provision of help to institutionalized women with intellectual disabilities in Taiwan. Social Science \& Medicine, 67(4), 540-545 . http://dx.doi .org/10.1016/j .socscimed .2008.04.018.

Cooper, S . C ., \& Koch, P . B . (2007) . "Nobody told me nothin": Communication about menstruation among low-income African American women. Women \& Health, 46(1), 57-78. http://dx .doi.org/10.1300/J013v46n01_05.

Chrisler, J . C., Marván, M. L., Gorman, J . A., \& Rossini, M . (2015) . Body appreciation and attitudes toward menstruation . Body Image, 12, 78-81 . http://dx .doi .org/10 $.1016 / \mathrm{j}$. bodyim .2014 .10 .003 .

Department of Higher Education and Training (2013) . Annual report 2012-2013 . HESA: Pretoria, South Africa . www .dhet . gov .za/ . . /Annual\%20Report\%202012\%20-\%202013 .pdf.

Eswi, A ., Helal, H ., \& Elarous, W . (2012). Menstrual attitude and knowledge among Egyptian female adolescents. The Journal of American Science, 8(6), 555-565 . http://dx.doi.org/10 .1136/bmjopen-2013-00460 .

Grant, M . J ., Lloyd, C . B ., \& Mensch, B . S . (2013) . Menstruation and school absenteeism: Evidence from rural Malawi . Comparative education review, 57(2), 260.

Higher Education South Africa (2007). Looking out for one another: Peer education, HIV and AIDS and South African campuses. HESA: Pretoria, South Africa . www .wsu .ac .za/ cha/publications/Peer\%20Education\%20TEXT .pdf .

Jewitt, S ., \& Ryley, H . (2014) . It's a girl thing: Menstruation, school attendance, spatial mobility and wider gender inequalities in Kenya . Geoforum, 56, 137-147 . http://dx .doi . org/10.1016/j .geoforum .2014.07.006. 
Johnston-Robledo, I ., Sheffield, K ., Voigt, J ., \& Wilcox- Constantine, J . (2007) . Reproductive shame: Self-objectification and young women's attitudes toward their reproductive functioning. Women \& Health, 46(1), 25-39 . http://dx .doi .org/10.1300/Jo13v46no1_03.

Kirk, J ., \& Sommer, M . (2006) . Menstruation and body awareness: Linking girls' health with girls' education. Royal Tropical Institute (KIT), Special on Gender and Health, 1-22.

Kumar, A ., \& Srivastava, K . (2011) . Cultural and social practices regarding menstruation among adolescent girls . Social Work in Public Health, 26(6), 594-604 . http://dx .doi .org/10.1080/ 19371918.2010 .525144 .

Laher, F., Todd, C. S ., Stibich, M. A., Phofa, R., Behane, X., Mohapi, L., . . . Gray, G. (2010). Role of menstruation in contraceptive choice among HIV-infected women in Soweto, South Africa . Contraception, 81(6), 547-551 . http://dx .doi . org/10 .1016/j .contraception.2009.12.010.

Lu, Z. Y. J. (2001). The relationship between menstrual attitudes and menstrual symptoms among Taiwanese women . Journal of Advanced Nursing, 33(5), 621-628. http://dx .doi . org/10.1046/j.1365-2648.2001.01705.x.

McMahon, S. A., Winch, P. J ., Caruso, B. A., Obure, A. F., Ogutu, E. A., Ochari, I. A., \& Rheingans, R . D . (2011) . "The girl with her period is the one to hang her head": Reflections on menstrual management among schoolgirls in rural Kenya . BMC International Health and Human Rights, 11(1), 7.

Mkhwanazi, N . (2010) . Understanding teenage pregnancy in a post-apartheid South African township. Culture, Health \& Sexuality, 12(4), 347-358 . http://dx .doi . org/10.1080/13691050903491779 .

Nagar, S ., \& Aimol, K. R . (2010) . Knowledge of adolescent girls regarding menstruation in tribal areas of Meghalaya. Stud Tribes Tribals, 8(1), 27-30.

O’Sullivan, L . F ., Cooper-Serber, E ., Kubeka, M ., \& Harrison, A . (2007) . Body concepts: Beliefs about the body and efforts to prevent HIV and pregnancy among a sample of young adults in South Africa. International Journal of Sexual Health, 19(2),69-80 .http://dx.doi.org/10.1300/J514v19no2_06.

Pinar, G ., Colak, M ., \& Oksuz, E . (2011). Premenstrual Syndrome in Turkish college students and its effects on life quality . Sexual \& Reproductive Healthcare: Official Journal of the Swedish Association of Midwives, 2(1), 21-27 . http:// dx .doi .org/10 $.1016 / \mathrm{j}$.srhc .2010.10.001.

Singh, A ., Kiran, D ., Singh, H ., Nel, B ., Singh, P ., \& Tiwari, P . (2008) . Prevalence and severity of dysmenorrhea: A problem related to menstruation, among first and second year female medical students, 52 (4) , 389-397.

Sharma, P ., Malhotra, C ., Taneja, D . K ., \& Saha, R . (2008) . Problems related to menstruation amongst adolescent girls. Indian Journal of Pediatrics, 75(2), 125-129. http://dx.doi.org/10 .1007/s12098-008-0018-5 .

Sommer, M . (2009) . Ideologies of sexuality, menstruation and risk: Girls' experiences of puberty and schooling in northern Tanzania . Culture, Health \& Sexuality, 11(4), 383-398. http://dx .doi .org/10 .1080/13691050902722372 . 
Sommer, M ., Hirsch, J . S ., Nathanson, C ., \& Parker, R . G . (2015) . Comfortably, safely, and without shame: Defining menstrual hygiene management as a public health issue. American Journal of Public Health, 105(7), 1302-1311 . http://dx .doi . org/10 $.2105 /$ AJPH .2014 .302525.

Sommer, M., Ackatia-Armah, N., Connolly, S ., \& Smiles, D . (2015). A comparison of the menstruation and education experiences of girls in Tanzania, Ghana, Cambodia and Ethiopia. Compare: A Journal of Comparative and International Education, 45(4), 589-609.

Wong, L. P ., \& Khoo, E. M . (2010). Menstrual-related attitudes and symptoms among multiracial Asian adolescent females. International Journal of Behavioral Medicine, 18(3), 246-253 . http://dx .doi .org/10 .1007/s12529-010-9091-z .

Wood, K ., \& Jewkes, R . (2006) . Blood blockages and scolding nurses: Barriers to adolescent contraceptive use in South Matters, 14(27), 109-118 . http://dx .doi .org/10 .1016/So968-8080(06)27231-8 .

Yamamoto, K , Okazaki, A , Sakamoto, Y , \&., \& Funatsu, M . (2009). The relationship between premenstrual symptoms, menstrual pain, irregular menstrual cycles and psychosocial stress among Japanese college students . Journal of Physiological Anthropology, 28(3), 129-136. http://dx.doi .org/10.2114/jpa2.28.129.

Yeung, D. Y., Tang, C. S. K., \& Lee, A. (2005). Psychosocial and cultural factors influencing expectations of menarche a study on Chinese pre-menarcheal teenage girls . Journal arch, 20(1), 118-135. http://dx .doi.org/10 .1177/0743558404271134 . 